\title{
Comparison of different vasodilators, endothelin antagonist, PDE5 inhibitior and SGC stimulators, in an animal model of secondary pulmonary hypertension: effects on "desaturation"
}

\author{
Eva Maria Becker, Johannes-Peter Stasch, Martin Bechem, Hubert Truebel*
}

From 5th International Conference on cGMP: Generators, Effectors and Therapeutic Implications Halle, Germany. 24-26 June 2011

\section{Background}

Treatment options approved for pulmonary arterial hypertension (PAH) failed in secondary forms of pulmonary hypertension $(\mathrm{PH})$ often related due to decrease in oxygenation. Therefore we established an animal model to evaluate different vasodilator mechanisms under experimental conditions of heterogeneous lung ventilation in respect to their "desaturation-potential".

\section{Methods}

Single-lung ventilation (right sided) was induced in 7-wk old minipigs (4-5 kg BW). In each animal 5 repetitive cycles of $10 \mathrm{~min}$. left lobe blockade were followed by 30 min. bilateral ventilation. Hemodynamics (e.g. mean pulmonary artery pressure (mPAP), blood pressure (BP)) and arterial hemoglobin saturation $(\mathrm{SaO} 2)$ were monitored continuously. We compared 5 different groups $(\mathrm{n}=6$ each): vehicle control group, the endothelin antagonist bosentan $(0.3,1,3,10 \mathrm{mg} / \mathrm{kg}$ i.v. $)$, the PDE5 inhibitor sildenafil $(3,10,30,100 \mu \mathrm{g} / \mathrm{kg}$ i.v. $)$, and the sGC stimulators BAY 41-8543 (1, 3, 10, $30 \mu \mathrm{g} / \mathrm{kg}$ i.v.) and riociguat $(1,3,10,30 \mu \mathrm{g} / \mathrm{kg}$ i.v.). The vasodilator doses were chosen to achieve equal BP reduction. Cumulative doses of vasoactive compounds were applied before successive unilateral ventilation and effects on desaturation (area under the $\mathrm{SaO} 2$ curve, AUCSaO2) and maximal hypoxic mPAP were compared to vehicle conditions in each animal.

* Correspondence: hubert.truebel@bayer.com

Bayer Schering Pharma AG, Cardiovascular Research, Wuppertal, Germany

\section{Results}

Single-lung ventilation resulted in transient increases in mPAP and desaturation (=increase in $\mathrm{AUC}_{\mathrm{SaO} 2}$ ). The vasodilators were compared in respect to their ability to decrease maximal hypoxic mPAP (positive treatment effect) and $\mathrm{AUC}_{\mathrm{SaO} 2}$ (unwanted desaturation effect). In contrast to vehicle treated control animals all vasodilators lead to a dose-dependent decrease in hypoxic mPAP (Figure 1) and an increase in $\mathrm{AUC}_{\mathrm{SaO} 2}$ during successive unilateral ventilation. Maximal changes in

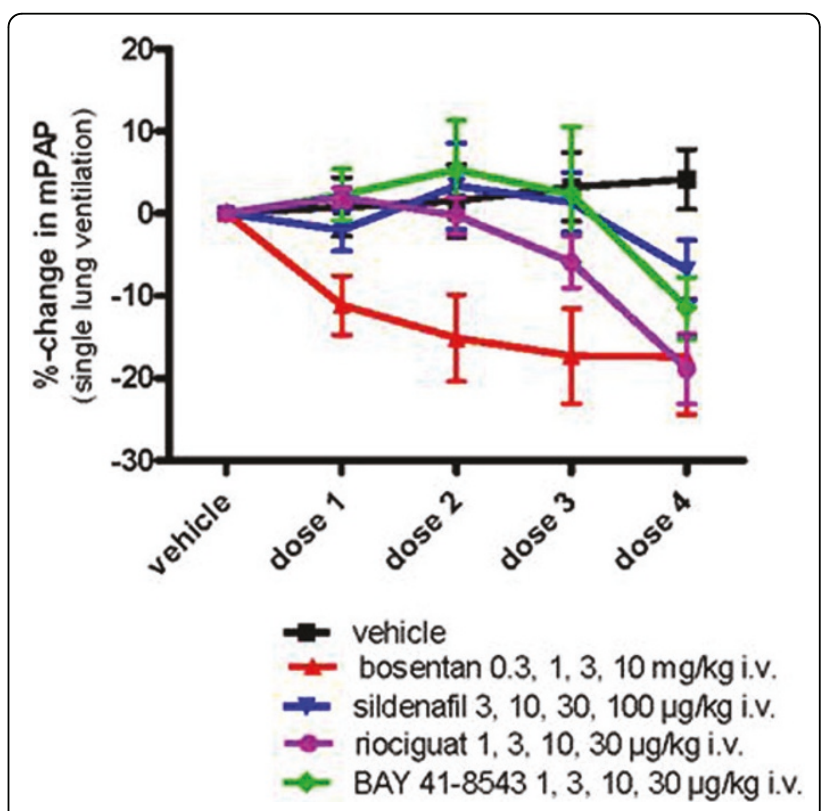

Figure 1 


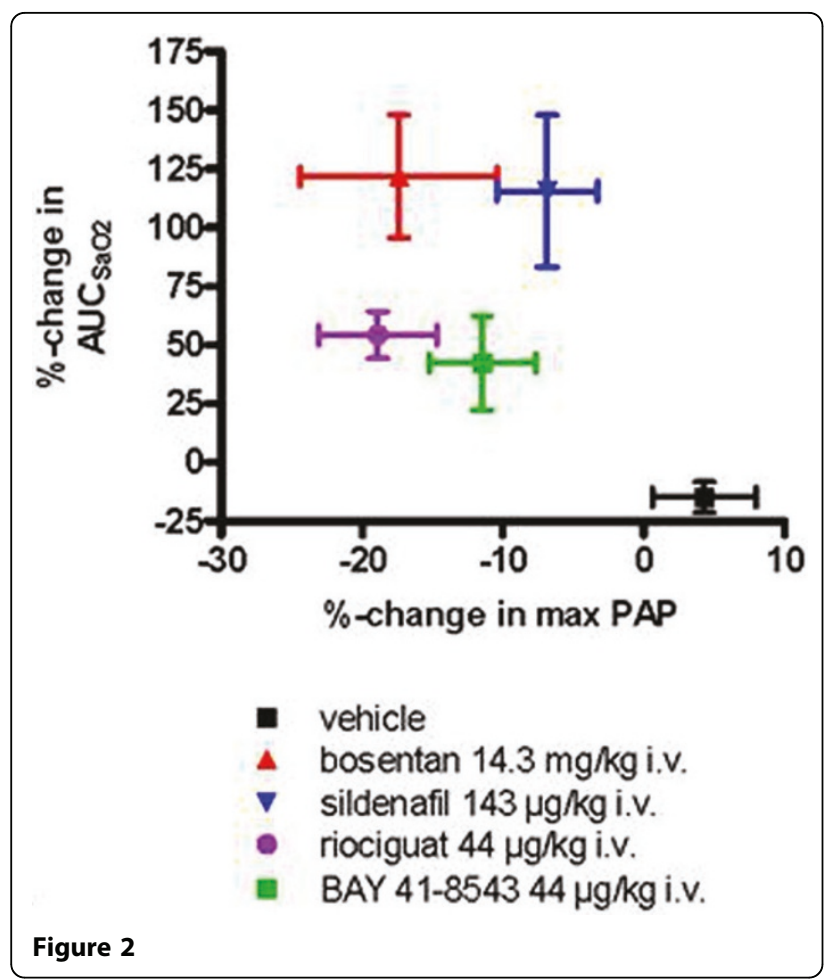

hypoxic mPAP associated with maximal increases in $\mathrm{AUC}_{\mathrm{SaO} 2}$ are shown in Figure $2($ mean $\pm \operatorname{SEM}(\mathrm{n}=6))$.

\section{Conclusion}

Beside the equal effects on BP, the studied compounds reduced hypoxic mPAP to a different extent with the strongest effect seen with the sGC stimulators (riociguat and BAY 41-8543) and bosentan. Furthermore, in comparison to bosentan and sildenafil the sGC stimulators were less likely to cause an unwanted decrease in $\mathrm{SaO}_{2}$. Explorations of these findings in patients with secondary PH might be warranted.

Published: 1 August 2011

- Convenient online submission

- Thorough peer review

- No space constraints or color figure charges

- Immediate publication on acceptance

- Inclusion in PubMed, CAS, Scopus and Google Scholar

- Research which is freely available for redistribution 